\title{
Further evidence for Xp21 location of Duchenne muscular dystrophy (DMD) locus: X;9 translocation in a female with DMD
}

\author{
BEVERLY S EMANUEL, ELAINE H ZACKAI, AND SAMUEL H TUCKER \\ Department of Pediatrics, University of Pennsylvania, The Children's Hospital of Philadelphia, \\ Philadelphia, Pennsylvania, USA.
}

SUMmARY Females who fully manifest Duchenne muscular dystrophy (DMD), an $\mathrm{X}$ linked disorder, are extremely rare. Cytogenetic studies are indicated in such females to rule out an $\mathrm{X}$ chromosome abnormality, which could render a female hemizygous for $\mathrm{X}$ linked genes. At present there are six reports describing females with Duchenne muscular dystrophy and an X;autosome translocation. ${ }^{1-6}$ Although each of these six rearrangements involves a different autosome, (chromosomes 11, 21, 1, 3, 5, and 6) they have in common a breakpoint at $\mathrm{Xp} 21$. We report here our observations of a further female with DMD who carries a de novo translocation between $\mathrm{Xp}$ and $9 \mathrm{p}$. The breakpoint in our patient is also located at Xp21, adding evidence for the assignment of this band as the site of the DMD gene.

\section{Case report}

The patient was the $3475 \mathrm{~g}$ product of a normal pregnancy and delivery, born at term to a G2, P1 18-year-old mother. The father was 22 years old at the time of her birth and family history was negative for neurological or muscular disease. Her neonatal course was unremarkable. She was first evaluated neurologically at 2 years of age. She did not begin to walk until 16 months of age and had only a five-word vocabulary. There was a history of clumsiness and frequent falls. Her height was on the 40th centile, weight on the 3 rd centile, and head circumference on the 50th centile. Neurological examination showed decreased deep tendon reflexes in the lower extremities and she had difficulty getting up from the floor. Her shoulder girdle muscles appeared weaker than normal. A CK level was determined which was 1400 , with a repeat of 900 .

She was seen again by a neurologist at 2 years, 9 months of age. At that time she was running, climbing, and moving around well, but had a Gower's sign on getting up from the floor. She was noted to have pseudohypertrophy of the calves, a

Received for publication 9 February 1983. Accepted for publication 10 March 1983. waddling gait with slight lordosis, 1 to $2+$ deep tendon reflexes, and decreased muscle in the shoulder girdles.

Laboratory studies included: CK 9000, SGOT 300, SGPT 400, and LDH 3114. Developmental quotient was 60 with a developmental age of 20 months. Soft tissue $x$-rays of the leg showed increased fatty bulk of the calves. A muscle biopsy revealed myopathic myopathy with inward migration of sarcolemma nuclei and increase in intramyocele and perimyocele connective tissue as well as adipose

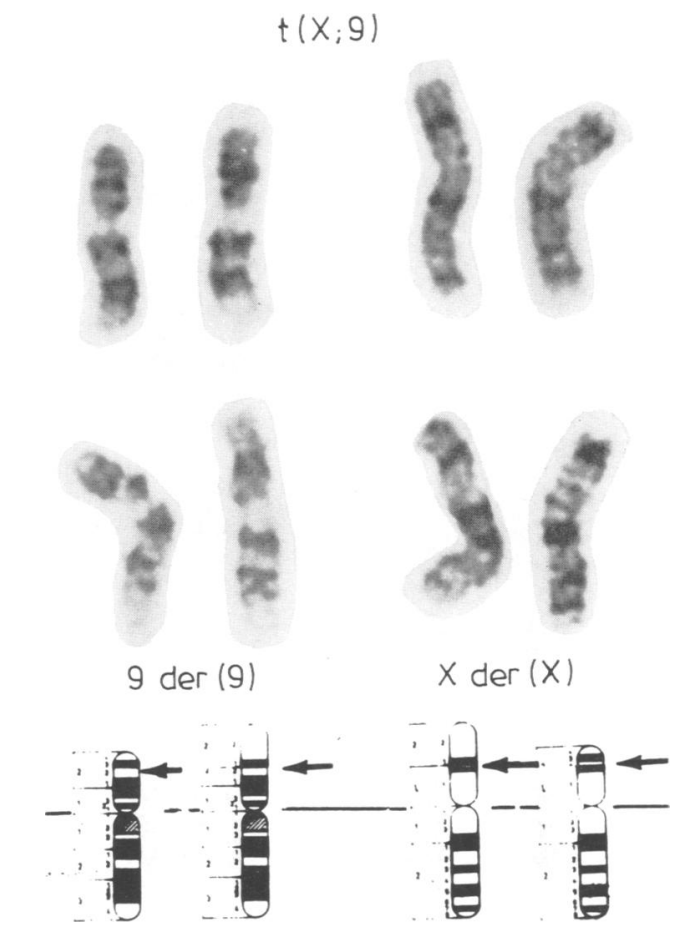

FIG 1 Partial $G$ banded karyotypes of the patient showing the $X$ and 9 chromosomes as compared to the ISCN (1978) idiogrammatic representations of the same chromosomes. Arrows on the two normal homologues indicate the breakpoints which result in the two derivative chromosomes, which have arrows at the site of the rearrangement. 
tissue. Histochemistry showed wide variation in the muscle fibre size with an increase in the number of central nuclei. The endomyocele connective tissue was also increased, and there were groups of regenerating fibres and occasional fibres undergoing phagocytosis. In the DPNH and ATPase reactions, both fibre types were affected. An EMG study was consistent with myopathy and the findings were thought to be typical of Duchenne muscular dystrophy.

When last evaluated at the age of 9 , she was a female with no dysmorphic features whose height was at the 10th centile and head circumference at the 80th. Her calf muscles were very large and firm. She was still walking without contractures with muscle strength 2 to $3+$ throughout. She is functioning in the moderately retarded range. Her two female sibs, one older and one younger, are

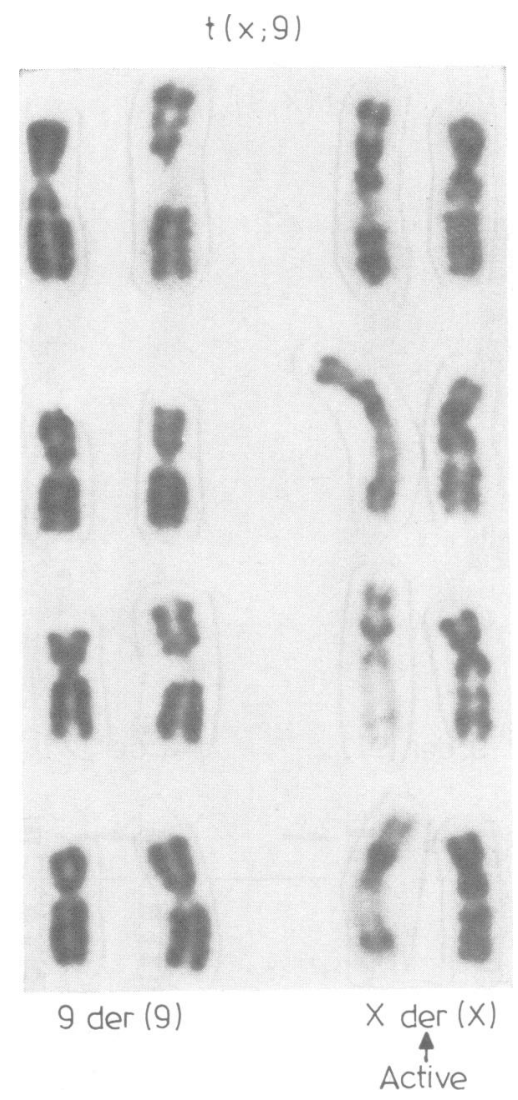

FIG 2 BrdU substituted Hoechst-Giemsa stained partial karyotypes for the $X$ and 9 chromosomes. Note that the normal $X$ chromosome is the late replicating or inactive $X$ chromosome in all examples. both neurologically normal. CK studies done on the mother and the two sibs were normal on several occasions.

The patient was referred for cytogenetic evaluation. A buccal smear was obtained which was $34 \%$ positive for Barr bodies (laboratory range for females is 15 to $40 \%$ ). Chromosome studies on this patient revealed a balanced translocation between the short arms of an $X$ and a 9, with a karyotype of $46, X, t(X ; 9)(\mathrm{p} 21 ; \mathrm{p} 22)$ (fig 1). The chromosomes of the parents and both sibs were normal. Thus, the translocation in this patient can be interpreted as a de novo event. Replication studies were undertaken to determine the pattern of $X$ chromosome inactivation in the patient. A terminal pulse of 5-bromodeoxyuridine was added to cells in culture, and the resulting chromosomal preparations were stained with the modified Hoechst-Giemsa technique previously described. ${ }^{7}$ In all but one of 82 differentially stained metaphases, the normal $\mathrm{X}$ chromosome was inactive or late replicating (fig 2 ).

\section{Discussion}

Our patient is the seventh reported female who manifests the full DMD phenotype as a result of structural alteration of an $\mathrm{X}$ chromosome. There i evidence from replication studies for selection favouring cells with an active, early replicating? derivative $X$ chromosome. Since the same $X$ chromosome is active in the majority of her cells, she expresses $\mathrm{X}$ linked genes from only the derivative $\mathrm{X}$ chromosome with regard to loci which are normally inactivated in female somatic cells. Thus, the abnormal $\mathrm{X}$ chromosome must carry the DMD mutation, and the normal $X$, inactive in the majority of cells, carries a normal allele. Using high resolution banding techniques, there is no evidence of deleted chromosomal material from either $\mathrm{X}$ chromosome as an alternative explanation for full manifestation of the DMD phenotype in this patient. In the six other females reported, selection also favours cells in which the translocated $\mathrm{X}$ is the active $\mathrm{X}$ chromosome (table). Therefore, these female DMD patients share a common pattern of $\mathrm{X}$ chromosomal inactivation, as well as an $\mathrm{X}$; autosome translocation.

The previously reported affected patients all had an $\mathrm{X}$ chromosomal breakpoint at p21. The one possible exception, the case described by Lindenbaum et al,$^{3}$ had a breakpoint either in Xp21 or very close to it in $\mathrm{Xp11.06}$. Our patient has the same breakpoint on the $\mathrm{X}$ chromosome, although the autosomes involved differ for all seven of these patients (table). In all cases where parental chromosome studies were performed, it was noted that the 
TABLE Comparison of pertinent findings between published cases and present case.

\begin{tabular}{|c|c|c|c|c|c|c|}
\hline \multirow{8}{*}{$\begin{array}{l}\text { Present case } \\
\text { Greenstein } \text { et al } 1 \\
\text { Verellen } \text { et al }{ }^{2} \\
\text { Lindenbaum } \text { et }^{\text {al }}{ }^{3} \\
\text { Canki et al }{ }^{4} \\
\text { Jacobs et al }{ }^{5} \\
\text { Zatz et al }{ }^{6}\end{array}$} & \multicolumn{2}{|c|}{ Autosome } & \multirow{2}{*}{$\begin{array}{l}X p 21 \\
+\end{array}$} & \multirow{2}{*}{$\begin{array}{l}\begin{array}{l}\text { De novo } \\
\text { rearrangement }\end{array} \\
+\end{array}$} & \multirow{2}{*}{$\begin{array}{l}\text { Mother a DMD } \\
\text { heterozygote }\end{array}$} & \multirow{2}{*}{$\begin{array}{l}\text { Abnormal } \\
X \text { active }\end{array}$} \\
\hline & 9 & p22 & & & & \\
\hline & 11 & q13 & + & + & - & + \\
\hline & 21 & p12 & + & Not stated & + & + \\
\hline & 1 & p14 & p11.06 or 21.07 & + & - & + \\
\hline & 3 & q13 & + & + & + & + \\
\hline & 5 & q35 & + & + & - & + \\
\hline & 6 & q21 & + & + & - & + \\
\hline
\end{tabular}

$\mathrm{X}$;autosome translocation had arisen de novo. Five of seven mothers of these DMD patients were not DMD carriers and there was a negative family history for the disease in all seven cases, implying that the DMD mutation as well as the chromosomal rearrangement arose de novo. These findings, together with the observation that no other site on the $\mathrm{X}$ chromosome has been implicated in allowing expression of DMD in a female, give support to the hypothesis that the translocation is the cause of the mutation and strongly suggests that the DMD gene is in $\mathrm{Xp} 21$.

There are two theoretical possibilities to explain these seven exceptional Duchenne females. The first is that their mothers are heterozygotes, and the maternal Duchenne carrying $\mathrm{X}$ chromosome is the one involved in the translocation. The second is that the translocation event itself causes the Duchenne mutation by interrupting or altering a structural gene, or by causing a position effect on a structural gene. The negative carrier testing of at least five of the mothers makes it likely that at least some of these pacients represent new mutations. The negative family history for these seven patients also strongly suggests the same interpretation.

If the translocation is not responsible for producing the DMD mutation, but only for ensuring expression of a pre-existing mutation, then any breakpoint on the $\mathrm{X}$ chromosome should result in the non-random selection of the inactive $\mathrm{X}$ chromosome required for hemizygous expression of $X$ linked genes. However, the observations that all of the rearrangements are de novo, show preferential expression of the translocated $\mathrm{X}$ chromosome, and involve an $\mathrm{X}$ chromosomal breakpoint at $\mathrm{p} 21$, give support to the hypothesis that the translocation event is probably the cause of the mutation, not merely the mechanism by which the phenotype is expressed. These findings favour the hypothesis that the gene which causes the DMD phenotype is located at Xp21.

The observation that seven different auıosomes are involved in these DMD translocations strongly suggests that the translocation itself causes the mutation by alteration or interruption of the structural gene, rather than a position effect on a pre-existing mutation. It thus seems likely that among the males who represent new mutations for Duchenne muscular dystrophy, one might eventually detect one who carries an $\mathrm{X}$;autosome rearrangement with involvement at Xp21 or a small deletion of $\mathrm{Xp}$. Although such studies have recently been attempted, ${ }^{8}$ no informative cases were found. It would be advisable to examine the chromosomes of all de novo cases of DMD using high resolution banding techniques.

\section{References}

1 Greenstein RM, Reardon MP, Chan TS, et al. An (X;11) translocation in a girl with Duchenne muscular dystrophy. Cytogenet Cell Genet 1980;27:268.

2 Verellen C, Markovic B, deMeyer R, Freund $\mathbf{M}$, Laterre C, Worton R. Expression of an X-linked recessive disease in a female due to non-random inactivation of the $\mathrm{X}$ chromosome. Am J Hum Genet 1978;30:97A.

${ }^{3}$ Lindenbaum RH, Clarke G, Patel C, Moncricff $M$, Hughes JT. Muscular dystrophy in an X;1 translocation female suggests that Duchenne locus is on $\mathrm{X}$ chromosome short arm. J Med Genet 1979;16:389-92.

4 Canki N, Dutrillaux B, Tivadar I. Dystrophie musculaire de Duchenne chez une petite fille porteuse d'une translocation $\mathrm{t}(\mathrm{X} ; 3)$ (p21;q13) de novo. Ann Genet (Paris) 1979;22:35-9.

5 Jacobs PA, Hunt PA, Mayer M, Bart RD. Duchenne muscular dystrophy (DMD) in a female with an X/autosome translocation: further evidence that the DMD locus is at Xp21. Am J Hum Genet $1981 ; 33: 513-8$.

- Zatz M, Vianna-Morgante AM, Campos P, Diament AJ. Translocation $(X ; 6)$ in a female with Duchenne muscular dystrophy: implications for the localisation of the DMD locus. J Med Genet $1981 ; 18: 442-7$.

7 Emanuel BS. Compound lateral asymmetry in human chromosome 6 . BrdU-dye studies of $6 \mathrm{q} 12 \rightarrow 6 \mathrm{q} 14 . \mathrm{Am} \mathrm{J}$ Hum Genet $1978 ; 30: 153-9$.

8 Spowart G, Buckton KE, Skinner R, Emery AEH. $X$ chromosome in Duchenne muscular dystrophy. Lancet 1982;i:1251.

Correspondence and requests for reprints to Dr B S Emanuel, Department of Pediatrics, The Children's Hospital of Philadelphia, Philadelphia, Pennsylvania, USA. 